\title{
Chemical, biological, and ecotoxicological assessment of pesticides and persistent organic pollutants in the Bahlui River, Romania
}

\author{
Mariana Neamtu • Ioan M. Ciumasu • Naela Costica $\cdot$ Mihai Costica $\cdot$ Magda Bobu • \\ Mircea N. Nicoara • Cezar Catrinescu • Kristin Becker van Slooten • \\ Luiz F. De Alencastro
}

Received: 25 April 2008 /Accepted: 10 December 2008 / Published online: 20 February 2009

(C) Springer-Verlag 2009

\begin{abstract}
Background, aim, and scope Current knowledge on environmental impacts of industrial activities in Romania, particularly persistent organic pollutants (POPs), indicates that environmental standards of the European Union are not systematically met. In our study area, additional sources of POPs are agriculture and domestic wastes. Very scarce information is available upon environmental contaminations and effects. In the present study, we investigated the chemical pollution and their eventual impact on the ecosystem by measuring POPs and by using biological indicators of pollution.

Materials and methods The survey was carried out at six main sample sites along the Bahlui River. Sediments were chemically analysed for their content in polychlorinated
\end{abstract}

Responsible editor: Walter Giger

M. Neamtu $\cdot$ M. Bobu $\cdot$ C. Catrinescu

Department of Environmental Engineering and Management,

Technical University of Iasi,

Bd. D. Mangeron 71A,

700050 Iasi, Romania

I. M. Ciumasu $(\bowtie) \cdot$ N. Costica $\cdot$ M. Costica $\cdot$ M. N. Nicoara

Faculty of Biology, Centre of Expertise for Sustainable

Exploitation of Ecosystems - CESEE,

"Alexandru Ioan Cuza" University Iasi,

Bulevardul Carol I nr 22,

700506 Iasi, Romania

e-mail: Ioan.M.Ciumasu@alumni.tum.de

K. B. van Slooten $\cdot$ L. F. De Alencastro

EPFL/ENAC/ISTE/CEL,

Institut des Sciences et Technologies de L'environnement (ISTE),

Ecole Polytechnique Fédérale de Lausanne (EPFL),

Station 2,

1015 Lausanne, Switzerland biphenyls (PCBs), polycyclic aromatic hydrocarbons (PAHs) and organochlorine pesticides (OCPs) - hexachlorocyclohexanes (HCHs) isomers and the dichlorodiphenyl trichloroethane (DDT) family. River water was biologically monitored at the level of phytoplankton and benthic invertebrates' communities. Water samples from six locations have been analyzed for algal species composition and correspondence to various water quality indices. Biological samples have been taken from the same locations so as to calculate the macroinvertebrate indices. In the most polluted areas, as revealed by previous methods, toxicity was tested by exposing the green alga Pseudokirchneriella subcapitata and the cladoceran Daphnia magna to various dilutions of water sample.

Results Important concentrations of POPs were identified only in sediments at river mouths (sites S5 and S6). Along the year, the sum of PCB concentrations ranged between 3 and $10 \mathrm{ng} / \mathrm{g} \mathrm{dw}$ (S5), and between 4 and $26 \mathrm{ng} / \mathrm{g} \mathrm{dw}$ (S6). Concentration of HCHs ranged between 0.4 and $3 \mathrm{ng} / \mathrm{g} \mathrm{dw}$ (both S5 and S6) with a higher contribution of the gamma$\mathrm{HCH}(30-70 \%)$, followed by beta-HCH $(20-50 \%)$. The beta-HCH isomer was found at lower concentrations or even not detected in outer city sites. DDTs were found at higher concentrations than $\mathrm{HCH}$ and ranged between 0.18 and $4 \mathrm{ng} / \mathrm{g}$ dw (S5) and between 0.56 and $18 \mathrm{ng} / \mathrm{g} \mathrm{dw}$ (S6). The parent compound, $\mathrm{p}, \mathrm{p}^{\prime}$-DDT, could be detected only in low concentrations (up to $5 \mathrm{ng} / \mathrm{g} \mathrm{dw}$ ) and contributed with less than $30 \%$ to the sum of DDTs in sediment. The principal contributors of the $\Sigma$ DDTs in sediment were $p, p^{\prime}-$ DDE, and p,p'-DDD. The o,p'-DDD and DDT isomers were minor contributors to the sum of DDT. PAHs were found at higher concentrations than DDTs and ranged between 6 and $36 \mathrm{ng} / \mathrm{g} \mathrm{dw}$ (S5) and between 36 and $155 \mathrm{ng} / \mathrm{g} \mathrm{dw}$ (S6). Fluoranthene was predominant (up to $40 \%$ ), followed by 
phenantrene (up to $30 \%$ ), naphthalene (up to $35 \%$ ), and benzo-(g,h,i)-perylene (up to $23 \%$ ). The saprobity index and the diatom index increased from springs to river mouth, indicating a decrease in the water quality, but within the limits of moderate pollution. The saprobity index varied between 1.99 at spring to 2.70 at mouth. The diatom index varied from 3.48 to 3.14 . The species' richness in phytoplankton has a less clear pattern along the river, but in general, it appears to be negatively influenced by pollution. At the level of biological consumer species, the analyses of the macroinvertebrates confirm the situation and the tendency shown with algae. In addition, the Shannon-Wiener index, the Pielou evenness index, and the McNaughton dominance index indicate a peculiar pattern: invertebrate communities appear to a have a more stable structure along the river, with visible shifts at springs and at river mouths. Water toxicity testing indicates low toxicity of river waters around the city of Iasi, with two notable exceptions: the point pollution at the domestic wastewater treatment discharge and at the old open-air deposit of domestic solid wastes. Another important result was that tested algae appeared to be more readily affected than tested cladoceran: $\mathrm{EC}_{50}$ (percent effluent) was 16 in algae and 28 in cladocerans. The slope of toxic effect was also much steeper in cladocerans (6) than in algae (1.8), which means that the toxic effect is more sudden on the tested invertebrates than on the tested algae.

Discussion Pollutant concentrations reported herein are lower or similar than those reported for the sediments by earlier studies (RIZA 2000; Dragan et al., Int J Environ Anal Chem 86:833-842, 2006). Ratios of individual PAH compounds indicate important pyrolytic inputs and suggest that PAHs in the area are derived from the combustion of fossil fuels. Biologically, the waters appear to be betamesosaprobic towards alpha-mesosaprobic according to the saprobic index classification and undergo moderate pollution according to the diatom index classification. Water quality decreases from springs to river mouths. Algal species richness index has a less clear pattern along the river. Water toxicity is low, but certain sources of point pollution require increased attention.

Conclusions The water quality is better than expected, probably because of the drop in pollution intensity following the collapse of local agricultural and industrial activity following the fall of communism in 1989. Nevertheless, further studies will be needed to confirm and refine our results. While this study draws no strident alarm, it appeals for high attention, particularly because the economic activity in the area is expected to increase.

Recommendations and perspectives Future close monitoring will be necessary for insuring compliance with the Water Framework Directive, and for refining standards and understanding of the local situation, but with relevance for the wider international community. On the basis of the situation described in the present study, we recommend that future studies dedicate specific efforts to point pollution and effluent toxicity, particularly around the city of Iasi. For a better understanding of pollution and its effects, we recommend pursuing the type of multidisciplinary investigations proposed by the present study: chemical, ecotoxicological, and ecological. We also recommend that new methods should be developed and/or refined, like the empirical determination of partitioning coefficients in water and soils, process-based toxicity methods in ecotoxicological assessments, searching for interactions between pollution, producers, and consumers in aquatic ecosystems. We also recommend preference for cheaper survey methods, as these will be more applicable locally.

Keywords Bahlui River - Benthic invertebrates · Biological indicators of pollution - Dichlorodiphenyl trichloroethane (DDT) · Ecotoxicological assessment · ESTROM · Hexachlorocyclohexanes (HCHs) · Persistent organic pollutants (POPs) - Polychlorinated biphenyls (PCBs) . Polycyclic aromatic hydrocarbons $(\mathrm{PAHs}) \cdot$ Organochlorine pesticides $(\mathrm{OCPs}) \cdot$ Pesticides · Phytoplankton · POPIASI project $\cdot$ River pollution $\cdot$ Romania $\cdot$ Water toxicity

\section{Background, aim, and scope}

Degradation of water quality and aquatic ecosystems, when it occurs, cannot be explained solely on the basis of monitoring of priority pollutants with analytical chemistry methods. Chemical analyses can identify substances and metabolites, but provide no information on their biological and ecological effects. Although it is difficult to always establish direct causality links between a list of pollutants and a list of biological phenomena, it is important to have such information together for further analysis and management purposes. The Water Framework Directive (WFD) recommends that monitoring and management should be carried out at river basin scales, and with integrated, chemical, and biological approaches, according to a common methodological platform now under development by the geographical intercalibration groups (WFD 2000).

While a cross-national methodological intercalibration exercise is beyond the scope of this paper, the study is meant instead to exercise, with limited resources, the type of interdisciplinary and integrated approach demanded in the WFD. The established objective was to produce a body of baseline information for the river Bahlui in north-eastern Romania (Fig. 1), which can be used as reference for more future interdisciplinary and integrated studies. This was done by using a limited number of methods from each type of approach. The approach combined chemical, ecotoxico- 


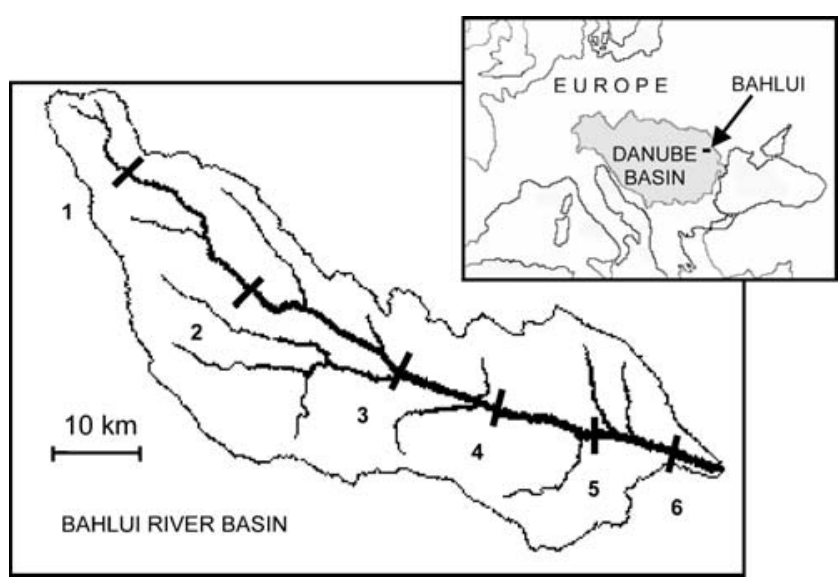

Fig. 1 The study area. The numbers indicate the locations of the main sampling sites

logical, and biological methods, basically from river spring to river mouth. Chemical analyses looked after persistent organic pollutants (POPs) like polychlorinated biphenyls (PCBs), hexachlorocyclohexanes (HCHs), and dichlorodiphenyl trichloroethane including its transformation products (DDTs) polycyclic aromatic hydrocarbons (PAHs). Biological survey aimed at identifying a general pattern of water quality level from spring to river mouth by means of ecological measures of plankton algal and benthic invertebrate communities. Ecotoxicological investigations aimed at assessing general water toxicity for different types of aquatic organisms - producer (photosynthetic) and consumer (non-photosynthetic) species.

During the last century, and especially during the last two decades, the study area underwent intense agricultural, industrial, and urban impacts. Agricultural practices in the Bahlui River Basin are associated with important soil erosion and use of pesticides. Older studies on nonoccupational (accidental) intoxications with pesticides in Romania revealed that in only $30 \%$ of cases the toxic substances were identified (Fabritius and Balasescu 1996), which proves the highly uncontrolled use of pesticides in Romania during the earlier years of the economic transition from planned to market economy. A comparative international study suggests for Romania a heavy historical use of DDT combined with retarded degradation in soils (Skrbic and Durisic-Mladenovic 2007). Another such study has shown a similar pattern of presence of PCBs in dairy products (butter) in most of the new (former socialist) members of the EU, and all within the accepted EU thresholds (Malisch and Dilara 2007). An earlier but more comprehensive study, focused on Iasi County, indicated that OCPs were present in all food and human samples (Hura et al. 1999). Given all these, a wide range of pollutants are to be expected in the study area.
Water quality in the study area is normally monitored by the local division of the National Romanian Waters Administration. However, given the limitations imposed by the economic transition and disciplinary traditions, independent information is sparse and narrow, usually at single locations, targeting only certain pollutants, and using only one method.

Locally, WFD regulations have already been under discussion in local context. While collaboration and implication of the local water authorities are essential, it is also very important to have available information verified by independent studies. This paper presents one of the first independent studies in this direction.

\section{Materials and methods}

\subsection{Study area}

The study area is along Bahlui River, in an area with both agricultural and industrial activity in north-eastern Romania, close to the city of Iasi, with 320,000 inhabitants. The river is $104 \mathrm{~km}$ long, with an average annual flow of $2.8 \mathrm{~m}^{3} \mathrm{~s}^{-1}$. According to the Geographic Intercalibration Group doing the intercalibration exercise aiming at harmonizing the highly diverse national water monitoring methods (WFD, Annex V, section 1.4.1), Bahlui River falls into the river intercalibration type R-E2 (Schmedtje and Liska 2005), which corresponds to medium-sized lowlands, altitude $<200 \mathrm{~m}$, with mixed geology, dominated by sand and silt. The Bahlui River Basin is part of the Prut River Basin ("River basin district" in WFD terminology), which corresponds to the local division of the National Water Administration (Administratia Nationala a Apelor). Major potential sources of point pollution are: urban water treatment plants (Iasi, Harlau, Targul Frumos, Podul Iloaiei, Vladeni, and Belcești), drug industry (uphill from Iasi city), energy plants (CET II Holboca, downhill from Iasi), wine industry (Cotnari), and zootechnical enterprises. The major sources of non-point pollution are agriculture and open waste dumps.

\subsection{Sampling}

For chemical analysis and the algal survey, samples were collected from six main locations along River Bahlui (see Fig. 1): Parcovaci (S1), Belcesti (S2), Bahluiet (S3), Catunu Banu (S4), Dacia (S5), and CET II (S6). The average distance between sampling sites is $10 \mathrm{~km}$, but longer to the springs and shorter to the river mouth. S3 is located at the mouth of river Bahluiet, the major tributary of Bahlui, which flows in an area with high population density and economic activity. The city of Iasi is located between S5 and S6. S1 (springs) is assumed to be the least polluted. 
Sampling was almost monthly during 2006 and 2007. For ecotoxicological testing, samples were collected only from the most polluted locations.

\subsection{Physical and chemical parameters}

During our survey, the following parameters were recorded in the field: dissolved oxygen, $\mathrm{pH}$, and conductivity (Table 1). $\mathrm{NO}_{3}{ }^{-}$levels recorded in April 2007 in various locations inside the city of Iasi were between 4.6 and $8.5 \mathrm{mg} \mathrm{dm}^{-3}$.

\subsection{Chemical survey}

Chemical investigation has been focused on the determination of PCB congeners, DDTs and 16 PAHs. The total PCB, DDT, and PAH contents were determined by summing up all respective congeners. Experimental conditions developed in this study were adapted for the different classes of pollutants from different methods that have been previously described elsewhere. Briefly, PCBs, organochlorine pesticides, and PAHs were extracted from the sediments by Soxhlet extraction with a mixture of hexane and acetone. Sulfur was removed by activated copper and a first clean-up was performed by GPC with Bio-Beads SX3. A fractionation step over silica gel allows the separation of the different compounds. This method with slight modifications, mainly in the fractionation step, is described in Kupper et al. (2008). Organochlorine compounds were measured by HRGC-ECD on two columns with different polarities. PAHs were determined by HPLC with fluorescence detection (Diercxsens and Tarradellas 1987) and by GC-MS. Quality control: In 2006, the method described above was employed in the Cambridge Isotope Laboratories Inc/Cerilliant Corporation, Second round international interlaboratory study on sediment, soil, and fish tissue reference materials (Grazio 2007). Our results were in very good agreement with those from other laboratories.

\subsection{Biological survey}

Biological stress is indicated by means of three phytoplankton indices and three benthic invertebrate indices. The ultimate aim of the study was to observe the variations along the river. Water organic load was assessed using the Pantle \& Buck saprobic index (Pantle and Buck 1955; Marcoci 1984; Spellerberg 2005). Extant literature shows that its calculation methods vary with countries (Rolauffs et al. 2004). Notably, we used plankton algae. Algal diversity is indicated by numerical species richness (Magurran 2004). Diatoms were measured by using Descy's diatom index (Descy 1979; AFNOR 2000), which we calculated for phytoplankton instead of benthic diatoms (to use the same samples used for species richness and saprobic indices). We used counts of 300 algal cells, colonies, filaments, or diatom valves, which is enough for good estimations of the composition of algal communities (Prygiel et al. 2002; US EPA 2002). Index values for phytoplankton are presented together with percentnormalized values: maximum and minimum possible values corresponding to $100 \%$ and $0 \%$, respectively. The maximum value is 4 in the saprobic index, 5 in the diatom index, and 114 for species richness (the overall number of recorded species at the six main sampling sites). In all, the minimum value is 1 . Invertebrates were described (2006) with: Shannon-Wiener index (Spellerberg 2005), Pielou's evenness index (Pielou 1977), and McNaughton dominance index (McNaughton 1968). Benthic invertebrate indices needed no normalization.

\subsection{Water toxicity}

We adapted an acute whole effluent toxicity (WET) procedure with standard test species (De Vlaming et al. 2000) to assess toxicity of river waters and effluents at different point pollution sources (discharges). Water sample dilutions were used in exposure tests: 72 -h growth of the

Table 1 Toxicity of water samples

\begin{tabular}{|c|c|c|c|c|c|c|c|c|c|c|}
\hline No. & $\begin{array}{l}\text { Parameter location } \\
\text { (near S6) }\end{array}$ & $\begin{array}{l}\text { Sampling } \\
\text { date }\end{array}$ & $\mathrm{pH}$ & $\begin{array}{l}\text { Dissolved } \\
\mathrm{O}_{2} \text { [ppm] }\end{array}$ & $\begin{array}{l}\text { Conductivity } \\
{\left[\mathrm{MS} \mathrm{cm}^{-1}\right]}\end{array}$ & $\begin{array}{l}\text { Tested } \\
\text { species }\end{array}$ & $\begin{array}{l}\mathrm{EC}_{10} \\
{[\%]}\end{array}$ & $\begin{array}{l}\mathrm{EC}_{50} \\
{[\%]}\end{array}$ & $\begin{array}{l}\mathrm{EC}_{90} \\
{[\%]}\end{array}$ & $\begin{array}{l}\text { Slope } \\
\text { (logistic) }\end{array}$ \\
\hline 1 & Holboca water treatment plant & 31.08 .07 & 7.6 & 3.2 & 1.03 & D.m. & 96 & $>100$ & $>100$ & - \\
\hline 2 & Tomesti—Bahlui & 31.08 .07 & 7.7 & 1.2 & 1.08 & D.m. & 16 & $>100$ & $>100$ & - \\
\hline 3 & Tomesti-waste deposit, leak canal & 31.08 .07 & 7.4 & $<1$ & 6.71 & D.m. & 19 & 28 & 40 & 6 \\
\hline 4 & Tomesti-waste deposit, leak canal & 04.08 .07 & - & - & - & P.s. & 4.5 & 16 & 55 & 1.8 \\
\hline 5 & Tomesti—Bahlui & 04.08 .07 & - & - & - & P.s. & 3.2 & 91 & $>100$ & 0.65 \\
\hline 6 & CET II-domestic water discharge canal & 04.08 .07 & - & - & - & P.s. & 1.5 & $>100$ & $>100$ & - \\
\hline
\end{tabular}

$\mathrm{EC}_{50}$ represents percentage of real sample inducing 50\% effect on Daphnia magna (D.m.) or Pseudokirchneriella subcapitata (P.s.) 
green alga Pseudokirchneriella subcapitata in flask assays (US EPA 1978, 2002) based on cell counts; 48-h acute lethality test Daphnia magna (OECD 2004). Using Microsoft Office Excel software, obtained values were fitted (where possible) with a logistic four-parameter equation: $y=\left\{\left[(A-D) /\left[1+(x / C)^{B}\right]\right\}+D\right.$, where $y$ is the ordinate axis (measured value), $x$ is the abscissa (percent concentration of water sample in the test), $A$ is the highest value and corresponds to the reference $(0 \%$ of water sample), $D$ is the lowest estimated value of survival, $B$ is the slope, and $C$ is the percent concentration of water sample corresponding to a $50 \%$ toxicity effect. Regressionbased estimates $\mathrm{EC}_{50}$ and $\mathrm{EC}_{20}$ are reported. $\mathrm{EC}_{x}$ were cross-checked with Probit (probability of percent classes) analysis - where possible (when there is no toxic effect, the curve computing is not possible).

\section{Results and discussions}

\subsection{Chemical survey}

For all classes of compounds, concentrations measured at S1-S4 are much lower than those within the S5-S6 area (Fig. 2). Therefore, further detailed results are only presented for the S5-S6 area.

The sum of PCB concentrations ranged (variations along the year) from 3 to $10 \mathrm{ng} / \mathrm{g} \mathrm{dw}$ (S5) and between 4 and $26 \mathrm{ng} / \mathrm{g} \mathrm{dw}$ (S6). Indicator PCB concentrations (28, 52, $101,138,153$, and 180) were higher than non-ortho- and mono-ortho-PCB concentrations constituting $70 \%$ to $80 \%$ of the total amount of PCBs (Table 2). These six PCB congeners are environmentally very persistent and predominantly present in most PCB mixtures and in environmental samples. These are also known as marker PCB, accounting for ca. $50 \%$ of the commercial PCB mixtures. It is difficult to correlate the congener profile with the source. In all samples, penta- and hexa-CBs predominated, followed by tri-, tetra-, and hepta-CBs.

Concentration of HCHs ranged (S5 and S6) between 0.4 and $3 \mathrm{ng} / \mathrm{g} \mathrm{dw}$, with a higher contribution of the gamma$\mathrm{HCH}(30-70 \%)$, followed by beta-HCH (20-50\%). The beta-HCH isomer was found at lower concentrations or even not detected outside the S5-S6 area.

DDTs were found at higher concentrations than $\mathrm{HCHs}$ and ranged between 0.18 and $4 \mathrm{ng} / \mathrm{g} \mathrm{dw}$ (S5) and between 0.56 and $18 \mathrm{ng} / \mathrm{g} \mathrm{dw}$ (S6). The parent compound, p,p'-DDT, could be detected only in low concentrations (up to $5 \mathrm{ng} / \mathrm{g} \mathrm{dw}$ ) and contributed with less than $30 \%$ to the sum of DDTs in sediment (Fig. 3). PAHs were found at higher concentrations than DDTs and ranged between 6 and $36 \mathrm{ng} / \mathrm{g} \mathrm{dw}$ (S5) and between 36 and $155 \mathrm{ng} / \mathrm{g} \mathrm{dw}$ (S6).

\subsection{Biological survey}

Phytoplankton indices have moderate values, with only slight variations along the river (Fig. 4). The saprobity index varies between 1.99 (S1) and 2.70 (S6), indicating alpha-mesosaprobic waters, which corresponds to moderate organic pollution. Another peak is at the Bahluiet River mouth (S3), indicating that when they confluence, Bahluiet waters are more organically loaded than those of Bahlui. This does not correspond to a peak in the POPs measured by us. The diatom index varies from 3.48 (S1) to 3.14 (S6), which falls, in terms of corresponding water quality class, on an average pollution. The two indices seem to agree. However, normalized diatom values are constantly higher along the river, which suggest that pollutants other than organic have important contributions to water quality degradation. Phytoplankton species richness is more variable along the river, between 28 (S3) and 50 (S4) species, with no clear pattern.

With macroinvertebrates, the main changes are at the upper and lower extremities of the river (Fig. 5). Between
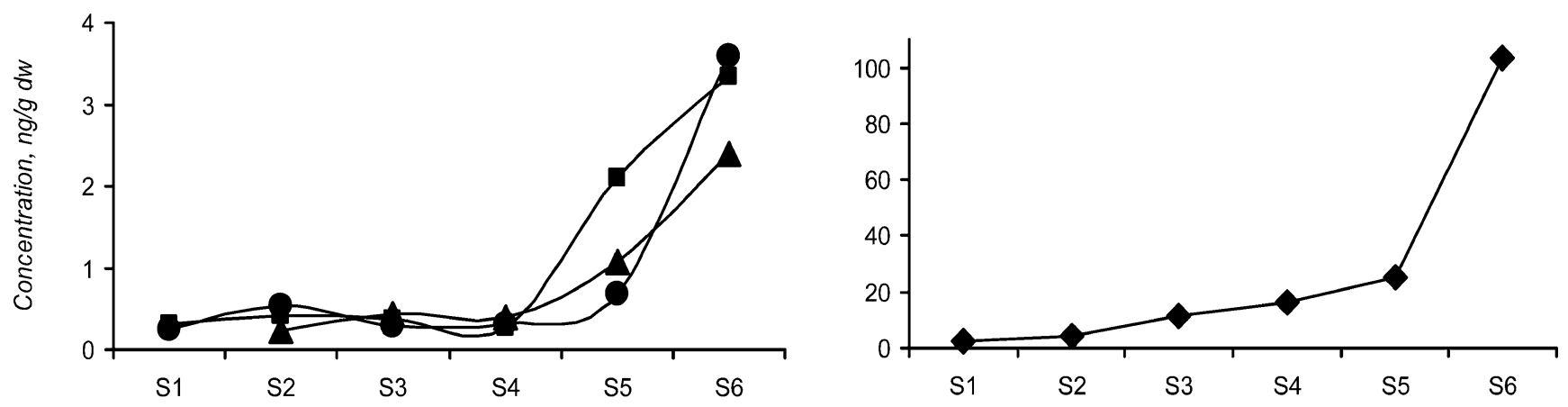

Sampling site

Fig. 2 Concentration of analyzed compounds found in sediments at the six sites: (filled circle) PCBs; (filled square) DDTs; (filled triangle) $\mathrm{HCHs}$; (filled diamond) PAHs 
Table 2 Percentage distribution of PCBs congeners in sediment samples from Bahlui River, S5 and S6, respectively

\begin{tabular}{|c|c|c|c|c|c|c|c|c|c|c|c|}
\hline & PCB 28 & PCB 52 & PCB 101 & PCB 149 & PCB 118 & PCB 153 & PCB 138 & PCB 156 & PCB 128 & PCB 180 & PCB 170 \\
\hline \multicolumn{12}{|l|}{ S5 } \\
\hline \multicolumn{12}{|l|}{2006} \\
\hline Feb & 28.84 & 18.21 & 4.62 & 5.13 & 3.35 & 12.47 & 7.46 & 0.00 & 4.94 & 4.04 & 4.16 \\
\hline April & 23.13 & 15.57 & 5.92 & 6.28 & 5.02 & 11.49 & 7.94 & 7.46 & 5.27 & 5.50 & 5.59 \\
\hline May & 18.45 & 14.08 & 8.50 & 6.17 & 7.98 & 11.72 & 10.38 & 1.76 & 0.00 & 11.31 & 4.58 \\
\hline July & 17.96 & 13.82 & 8.53 & 0.00 & 8.04 & 11.58 & 10.31 & 0.00 & 0.00 & 11.19 & 4.99 \\
\hline Sept & 10.09 & 10.29 & 13.76 & 14.07 & 5.06 & 18.52 & 13.44 & 0.00 & 0.00 & 8.65 & 3.22 \\
\hline Oct & 20.11 & 10.35 & 14.57 & 14.94 & 4.00 & 20.36 & 14.18 & 0.00 & 0.00 & 8.36 & 1.56 \\
\hline Nov & 15.06 & 15.68 & 13.00 & 8.12 & 7.66 & 14.30 & 13.73 & 0.00 & 0.00 & 8.56 & 3.88 \\
\hline Dec & 8.44 & 18.52 & 16.15 & 6.41 & 10.80 & 12.02 & 11.05 & 0.00 & 0.00 & 8.28 & 3.17 \\
\hline \multicolumn{12}{|l|}{2007} \\
\hline March & 9.19 & 25.72 & 21.85 & 7.34 & 7.56 & 8.26 & 7.08 & 0.90 & 1.13 & 4.71 & 2.72 \\
\hline April & 7.40 & 26.58 & 26.75 & 7.90 & 9.10 & 6.69 & 5.34 & 0.53 & 1.27 & 2.56 & 2.09 \\
\hline May & 31.44 & 10.44 & 7.54 & 7.23 & 8.35 & 10.87 & 7.60 & 3.39 & 3.45 & 7.42 & 7.20 \\
\hline June & 20.99 & 12.46 & 6.74 & 0.00 & 6.04 & 6.98 & 5.28 & 0.55 & 0.00 & 5.72 & 0.00 \\
\hline Sept & 25.23 & 13.60 & 8.48 & 4.29 & 8.55 & 10.61 & 7.65 & 2.34 & 2.05 & 7.80 & 4.28 \\
\hline Oct & 27.68 & 15.68 & 9.10 & 2.37 & 8.68 & 10.43 & 7.69 & 1.65 & 1.13 & 8.06 & 2.36 \\
\hline Nov & 16.27 & 17.71 & 11.32 & 0.00 & 10.31 & 13.71 & 12.40 & 0.82 & 0.00 & 11.63 & 0.00 \\
\hline \multicolumn{12}{|l|}{ S6 } \\
\hline \multicolumn{12}{|l|}{2006} \\
\hline $\mathrm{Feb}$ & 27.71 & 0.00 & 0.00 & 16.18 & 0.00 & 32.30 & 29.41 & 4.57 & 0.00 & 0.00 & 17.54 \\
\hline April & 21.38 & 14.06 & 4.74 & 9.56 & 0.00 & 25.97 & 20.32 & 0.82 & 0.00 & 0.00 & 3.15 \\
\hline May & 16.00 & 12.66 & 8.42 & 10.61 & 5.42 & 18.09 & 15.52 & 0.00 & 0.00 & 0.00 & 7.67 \\
\hline July & 13.08 & 11.13 & 8.63 & 9.92 & 6.87 & 14.32 & 12.80 & 5.12 & 0.00 & 3.68 & 8.21 \\
\hline Sept & 10.66 & 11.17 & 7.06 & 7.15 & 3.88 & 0.00 & 0.00 & 0.00 & 0.00 & 23.97 & 9.62 \\
\hline Oct & 10.11 & 8.96 & 5.77 & 8.99 & 2.66 & 17.31 & 15.80 & 0.00 & 1.38 & 20.92 & 6.97 \\
\hline Nov & 8.13 & 7.37 & 5.24 & 7.39 & 3.16 & 12.94 & 11.94 & 0.00 & 1.05 & 15.35 & 6.04 \\
\hline Dec & 5.94 & 13.04 & 11.37 & 4.51 & 7.60 & 8.46 & 7.79 & 0.93 & 3.05 & 5.83 & 2.23 \\
\hline \multicolumn{12}{|l|}{2007} \\
\hline March & 14.19 & 8.56 & 6.58 & 8.38 & 5.04 & 15.79 & 10.57 & 1.67 & 1.68 & 17.20 & 7.81 \\
\hline April & 9.95 & 25.36 & 19.78 & 7.11 & 6.91 & 8.93 & 7.81 & 1.05 & 1.07 & 5.62 & 2.99 \\
\hline May & 11.78 & 7.93 & 6.26 & 8.76 & 3.94 & 17.41 & 11.56 & 1.10 & 1.10 & 20.44 & 8.01 \\
\hline June & 9.34 & 6.05 & 21.45 & 0.00 & 1.51 & 10.21 & 13.87 & 1.60 & 0.00 & 26.73 & 0.00 \\
\hline Sept & 10.43 & 6.90 & 14.64 & 3.93 & 2.60 & 13.44 & 12.84 & 1.38 & 0.49 & 23.91 & 3.59 \\
\hline Oct & 10.51 & 10.10 & 14.83 & 2.24 & 10.34 & 12.33 & 10.51 & 1.76 & 0.28 & 19.29 & 2.04 \\
\hline Nov & 10.61 & 14.33 & 15.08 & 0.00 & 20.53 & 10.87 & 7.45 & 2.27 & 0.00 & 13.21 & 0.00 \\
\hline
\end{tabular}

S1 and S2, there is an increase of the Shannon-Wiener and McNaughton Indices, and a decrease of the Pielou index. In ecological terms, this suggests a slight shift of the invertebrate community to a structure with lower species evenness. Between S2 and S5, the values are rather constant. Between S5 and S6, Shannon-Wiener and McNaughton indices decreased, while the Pielou index increased (a reverse of the situation between S1 and S2). In other words, the middle segment of the river (from S2 to $\mathrm{S} 5$ ) is characterized by communities with lower evenness.

\subsection{Water toxicity}

Water toxicity was low, with marginal or no toxic effects in most sampling sites, as seen in a selection of our measurements (see Table 1; Figs. 6 and 7). Important toxicity was revealed, however, in effluents from a canal near the openair deposit of domestic wastes in Tomesti, close to S6. This sample was found to be highly toxic for both algae and daphnia. The different toxicity patterns (parameters of the fitted curve) obtained with the two species, i.e., higher $\mathrm{EC}_{50}$ 
Fig. 3 Percentage distribution of DDT analogues in sediment samples from Bahlui River
March $\square$ April $\mathbf{\square}$ May $\mathbf{0}$ June $\mathbf{\square}$ Sept $\mathbf{0}$ Oct $\square$ Nov

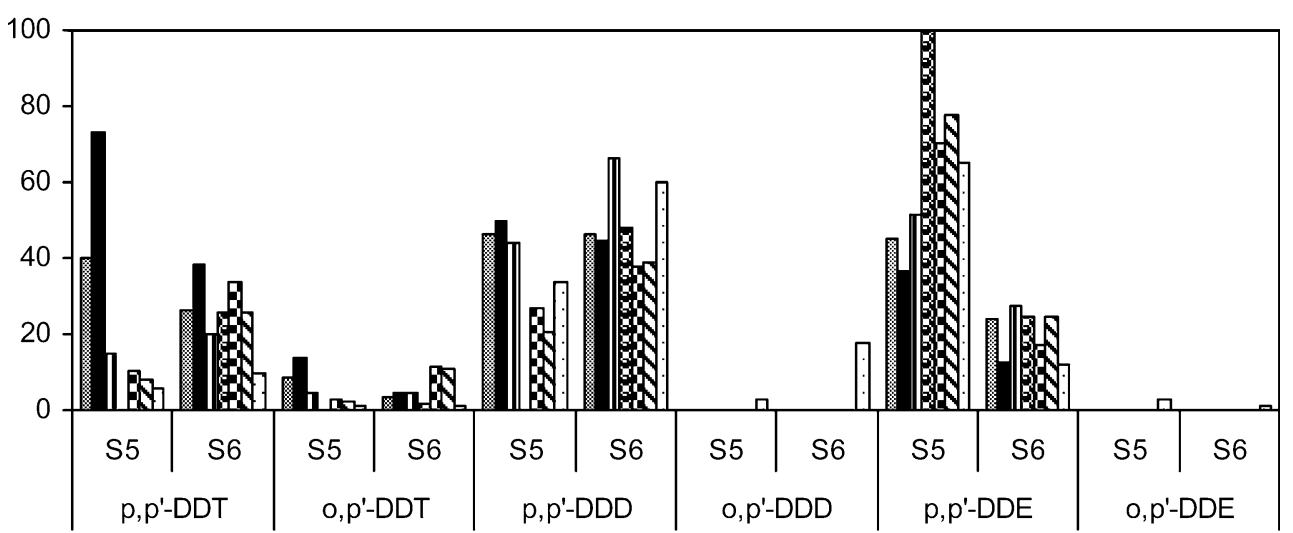

and lower slope of the algal toxicity curve, suggest nonsimilar toxicity mechanisms. As seen in Table 1, river waters downstream from this source of pollution appear to have increased toxicity, as obtained with algal toxicity tests immediately down the river. However, toxicity is lower for D. magna than for P. subcapitata. The samples show higher toxicity for the tested algae than for the tested daphnia: $\mathrm{EC}_{50}$ was 16 in algae and 28 in cladocerans. The slope of toxic effect was also much steeper in cladocerans (6) than in algae (1.8).

\section{Discussion}

According to the Water Framework Directive, clean water means ecologically clean water. Quantitative data on the looked-for set of pollutants provide grounds for future technical mitigation of pollution at the known sources. But even when quasi-all pollution sources would be known, they have no environmental meaning unless provided with

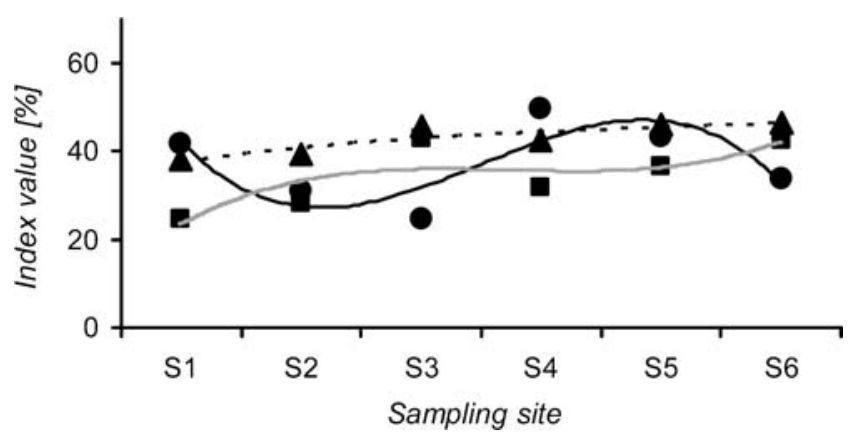

Fig. 4 Normalized (percent) values of indices calculated for phytoplankton algae, from river springs (S1) to river mouth (S6): (filled circle, continuous gray line) species richness index, (filled square; continuous black line) saprobity index, (filled triangle; interrupted black line) diatom index. Percent values correspond to the pollution classes used in the diatom index: no/low pollution $(<25 \%)$; moderate pollution (25-50\%); strong pollution (50-75\%); very strong pollution $(>75 \%)$ ecological measures of the pollution effects on water ecosystems. Ecological and biological data indicates the overall effects of pollution, i.e., the cumulative effects of the looked-for and non-looked-for pollutants in space and time. We have used (1) chemical and ecological methods to identify the general pollution patterns (main potential pollutants and overall pollution) and (2) the high sensitivity of ecotoxicological methods (acute toxicity) to unveil sources of pollution that would otherwise remain hidden (e.g., diluted out in the river or by episodic character).

With the looked-for chemical pollutants, we have measured low pollution levels of individual pollutants or classes of pollutants. No legal threshold has been crossed.

POP levels reported herein are lower or similar to those reported in earlier studies (RIZA 2000; Dragan et al. 2006).

In general, PCB concentrations were relatively low. The low levels of PCBs correspond with low or no longer existing production and usage of PCBs in Eastern European countries. Low PCB levels have also been observed in sediments from the Danube and Volga deltas, while PCB concentrations in sediments from the Rhine delta (The Netherlands) were up to $200 \mathrm{ng} / \mathrm{g} \mathrm{dw}$ (Winklers et al. 1998).

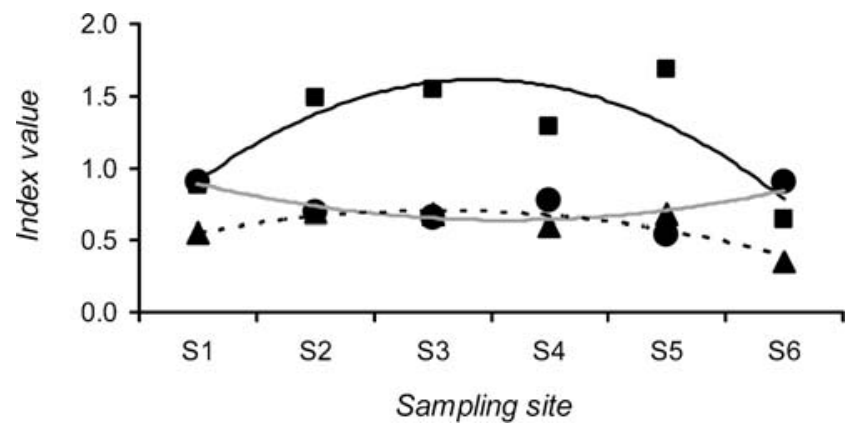

Fig. 5 Invertebrate indices from river springs (S1) to river mouth (S6): (filled square; continuous black line) Shannon-Wiener; (filled circle; continuous gray line) Pielou; (filled triangle; interrupted black line) McNoughton 


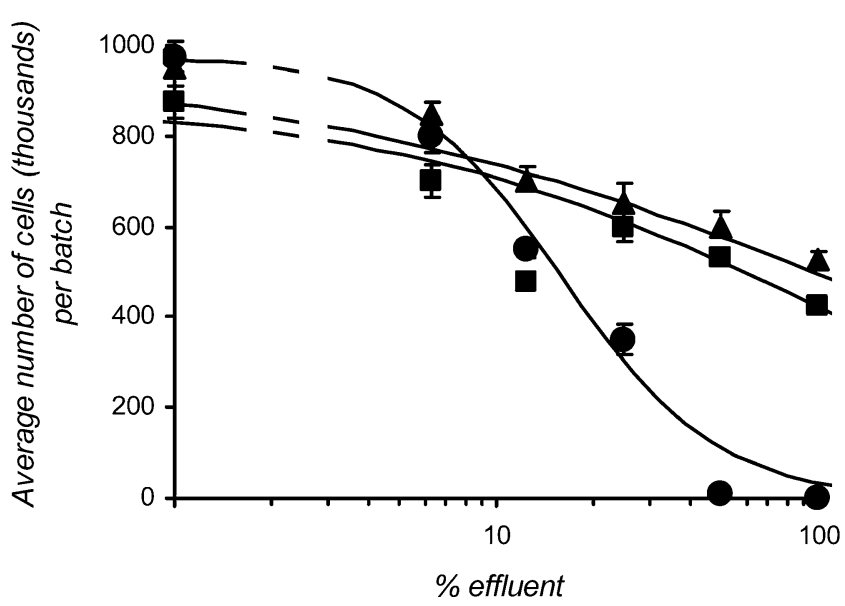

Fig. 6 Toxic effect of various percentages of effluent upon the growth of Pseudokirchneriella subcapitata (average number of cells per batch; $n=3$ ), incubated $72 \mathrm{~h}$. Effluents are from: (filled circle) Tomesti-waste deposit leak canal; (filled square) Tomești-Bahlui River; (filled triangle) CET II-discharge

The principal contributors of the sum of DDTs in sediment were $\mathrm{p}, \mathrm{p}^{\prime}$-DDE and $\mathrm{p}, \mathrm{p}^{\prime}-\mathrm{DDD}$. The o, $\mathrm{p}^{\prime}$-DDD and $\mathrm{o}, \mathrm{p}^{\prime}$-DDT isomers were minor contributors to the sum of DDTs. The data are similar to previous findings for other European rivers.

In our measurements, fluoranthene was the predominant PAH (up to $40 \%$ ), followed by phenantrene (up to $30 \%$ ), naphthalene (up to $35 \%$ ), and benzo-(g,h,i)-perylene (up to $23 \%)$. Combustion of fossil fuels, waste incineration, and oil spills are the potential sources of PAHs in the environment. Because of their hydrophobicity, PAHs, too, show high persistence in sediments. The possible source of PAHs in sediments may be assessed by the ratios of individual PAH compounds (Benlahcen et al. 1997). A ratio of phenantrene/antracene $<10$ and fluoranthene/pyrene $>1$

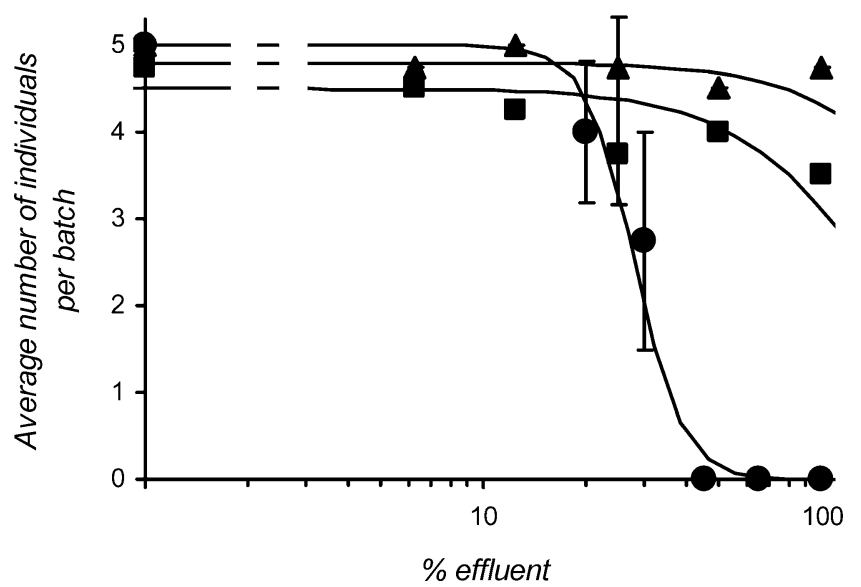

Fig. 7 Toxic effect of various percentages of effluent upon the survival of Daphnia magna (average number of individuals per batch), incubated $48 \mathrm{~h}$. Effluents are from: (filled circle) Tomesti-waste deposit leak canal; (filled square) Tomești-Bahlui River; (filled triangle) CET II-discharge may indicate that PAH contamination is from combustion processes (Benlahcen et al. 1997). Our results met the above criteria. For the fluoranthene/pyrene ratios, values greater than 1 are attributed to pyrolytic origin while values less than 1 are related to petrogenic sources. In a majority of sites, the fluoranthene/pyrene ratios were $>1$, indicating important pyrolytic inputs. In addition, all values of benzo (a)pyrene/benzo(g,h,i)perylene ratio were between 1.25 and 5 , which were similar to the range (1.2-5) reported for wood burning and sediments affected by coal burning (Maher and Aislabie 1992). The results suggest that PAHs in the area are derived from the combustion of fossil fuels.

The sudden increase in pollutants in sediments at sample stations S5 and S6 has no clear ecological correspondence in the phytoplankton and benthic invertebrates. This is not a surprise because measured chemical values are still low and because we only measured a part of the potential pollutants (and also only in sediments). This suggests that the total loads of the pollutants measured by us are still not large enough (as a share of the summed-up pollutants in the river) to have a distinctive effect on the general pattern of pollution and water quality.

We should also keep in mind that even with low pollution levels, pollution impacts upon aquatic ecosystems and human health because of accumulation pollutants in organisms by two dynamics: biophysical extraction of pollutants of organisms from their environment (concentrator species) and by biomass transfer down the trophic chains. For example, invertebrates and fish can act as accumulator species. When consumed by humans, such pollutant accumulations can have important effects on human health. In our results, consumer species and primary producer species both indicate moderate pollution, but they differ in pattern details. Phytoplankton indices indicate a rather constant slight increase of pollution from S1 to S6, always within moderate pollution ranges and with no particular change in the S5-S6 area. Invertebrate indices indicate also a constant level of moderate pollution, but without a visible increase from S2 to S5. Instead, some changes showed up at $\mathrm{S} 1$ and $\mathrm{S} 6$.

For environmental managers in the study area, such complex pollutant-effect relations "on-site" signify that pollution must be addressed systemically, not only focused on the most known pollutants.

Regarding the immediate effects of pollution, these are less present within the river water body at the pollution level indicated by our chemical and ecological measures. However, certain point pollution sources appear to require further in-depth studies, like the waste deposit from Tomesti and the wastewater treatment plants of the city of Iasi. Toxic discharges (leakages) from the waste deposit are probably episodic (during rainy periods). Planned technological updating of these two public enterprises is not 
achieved yet. Until then, ecotoxicological assessments should be carried out on the spot. Ecotoxicological tests with single species are not as helpful in waters with average quality as in heavily polluted ones because (1) average pollution produce no visible acute toxicity effect and (2) its results cannot be extrapolated to community and ecosystems. Instead, their sensitivity is appropriate for rapid identification of high pollutant discharges when these occur. For this particular case, the fact that there is no consensus in Europe on which toxicity test to recommend as mandatory for hazardous wastes is not helping, but should be no hindrance either. Testing toxicity of solid waste leachate (often containing metals, especially when there was no selective discharge) with $D$. magna raises the problem that dissolved oxygen drops below $3 \mathrm{mg} \mathrm{dm}^{-3}$, which invalidates clear toxicity measurements according to OECD 202 guidelines, unless the sample is oxygenated before testing. In any case, the test provides useful information on the general effects of leachates upon the tested organisms (Seco et al. 2003). Future investigations will be needed to evaluate ecotoxicological risks of these leachates for the surrounding environment.

Last but not least, water toxicity appears to be higher for the tested algae and less for Daphniae. Although results with single species toxicity tests are not sufficient to allow extrapolations to ecosystems, such sensitivity differences are important. Pollution affects producer species rather directly, while it affects consumers firstly indirectly by restrictions on the available food, and only later directly by toxic effects (Preston 2002). Our ecological measurements also indicated that primary producers reacted stronger than consumers at the presence of pollutants.

\section{Conclusions}

The water quality in the catchment of Bahlui River is better than expected, probably because of the drop in pollution intensity following the collapse of local economic activity following the fall of communism in 1989. Nevertheless, further studies will be needed to confirm and refine our results. While this study draws no strident alarm, it demands increased attention because the economic activity in the area is expected to increase. Future close monitoring will be necessary for insuring compliance with WFD, and for refining standards and understanding of the local situation, but with relevance for the wider international community.

\section{Recommendations and perspectives}

In perspective, several lessons can be drawn from the present study. Regarding pollution itself, specific attention needs to be paid to point pollution, as observed around the city of Iasi. For specific substances of interest, it could be highly useful to develop an equilibrium partitioning method, based on local conditions. Partitioning coefficients determined empirically (on the basis on sensitivity distributions) in water and soils will allow derivative calculations of soil quality standards from aquatic quality standards determined with aquatic toxicity tests. This will allow quality standards to be monitored with fewer resources, which will then be able to be used for extending the scope of environmental monitoring actions.

Regarding pollution effects to aquatic communities, specific attention must be paid to identifying the interactions between pollution, producers, and consumers in aquatic ecosystems. A closer attention must also be paid to monitoring diatom communities because they dominate phytoplankton communities. Fish populations should be included in future monitoring, together with the other biological elements recommended by the intercalibration exercise (Birk 2007).

Regarding ecotoxicological testing, whole effluent toxicity tests may provide a basis for more in-depth investigations, like toxicity identification evaluations to identify the particular toxic components in municipal and industrial effluents, and the detailed toxicological effects important for water quality management (e.g., Tinsley et al. 2004). Also, the battery of toxicity tests used in this study was rather limited and should be extended during future investigations.

As the present study has been carried out with relatively modest budgets, it is also important to remark that, in the process of improving methods for WFD, low budget methods should and can be developed for the implementation of WFD. This is important in any country, irrespective of their wealth. In Romania, it has been reported that more than $60 \%$ of waters are not at risk in all river basins and that about $20-40 \%$ of the waters are heavily modified which means that much work remains to be done and resources to be spent.

Finally, the present work and the ones to follow will not have only local importance. This is because the Prut River Basin, of which the Bahlui River is a contributor, is also an international component of the Lower Danube Basin, collecting waters from both EU (Romania) and non-EU countries (Republic of Moldova and Ukraine). Here, WFD is being implemented either through EU countries (Romania and Bulgaria) or through the International Commission for the Protection of Danube River in which all non-EU countries are politically committed to implement the WFD as such.

Acknowledgments This work was financed by the Swiss National Science Foundation, the Swiss Agency for Development and Cooperation, and the Romanian Ministry for Education and Research within the framework of the Swiss-Romanian cooperation programme on "Environmental Science and Technology in Romania-ESTROM". 
The reported study was performed in the project POPIASI focusing on pesticides and persistent organic pollutants in the river Bahlui. In the second part of the work, the Romanian authors' activity was facilitated through formally unrelated but scientifically complementary developments of laboratory facilities funded through the project 634 of the CEEX programme (2005-2008) of the Romanian Ministry of Education and Research. We are grateful to Mihai Erhan, Gabriel Plavan, and Irina Rosca for helping with water samples work in the field and species determinations in the laboratory, at the Science Shop of the Faculty of Biology, "Alexandru Ioan Cuza" University of Iasi; Cristina Cobzaru for helping with the ecotoxicological work; Benoît Ferrari and Nicolae Stefan for logistic support; Dominique Grandjean for helping in the chemical analysis; and Antonius Kettrup and Dioxin Laboratory from GSF-Institute for Ecological Chemistry, Germany for constructive comments on earlier laboratory and editorial work.

\section{References}

AFNOR (2000) Norme française NF T 90-354. Qualité de l'eau. Détermination de l'Indice Biologique Diatomée (IBD)

Benlahcen KT, Chaoui A, Budzinski H, Garrigues P (1997) Distribution and sources of polycyclic aromatic hydrocarbons in some Mediterranean coastal sediments. Mar Pollut Bull 34:298-305

Birk S (2007) River basin management tools: intercalibration. UNDP I GEF Danube Regional Project, April 2007, http://www.undp-drp. org/pdf/1.1 River\%Basin\%20Management\%20-\%20Phase \%202/ 2.2_Intercalibration_20070507-FinRep-f.pdf. Accessed on 09.02 .2008

De Vlaming V, Connor V, DiGiorgio C, Bailey HC, Deanovic LA, Hinton DE (2000) Application of whole effluent toxicity test procedures to ambient water quality assessment. Environ Toxicol Chem 19:42-62

Descy JP (1979) A new approach to water quality estimation using diatoms. Nova Hedwigia 64:305-323

Diercxsens P, Tarradellas J (1987) Soil contamination by some organic micropollutants related to sewage sludge spreading. Int J Environ Anal Chem 28:143-159

Dragan D, Cucu-Man S, Dirtu AC, Mocanu R, van Vaeck L, Covaci A (2006) Occurrence of organochlorine pesticides and polychlorinated biphenyls in soils and sediments from Eastern Romania. Int J Environ Anal Chem 86:833-842

Fabritius K, Balasescu M (1996) Acute non-occupational intoxications with pesticides in Romania: a comparative study from 19881993. Toxicol Lett 88:211-214

Grazio J (2007) Report on the second round international interlaboratory study on sediment, soil and fish tissue reference materials. Cambridge Isotope Laboratories Inc./Cerilliant Corporation, USA

Hura C, Leanca M, Rusu L, Hura BA (1999) Risk assessment of pollution with pesticides in food in the Eastern Romania area (1996-1997). Toxicol Lett 107:103-107

Kupper T, de Alencastro LF, Gatsigazi R, Furrer R, Grandjean D, Tarradellas J (2008) Concentrations and specific loads of brominated flame retardants in sewage sludge. Chemosphere 71 (6): $1173-1180$

Magurran AE (2004) Measuring biological diversity. Blackwell, Oxford, UK, pp 74-75
Maher WA, Aislabie J (1992) Polycyclic aromatic hydrocarbons in nearshore marine sediments of Australia. Sci Tot Environ 112:143164

Malisch R, Dilara P (2007) PCDD/Fs and PCBs in butter samples from new European Union member states and a candidate country: analytical quality control, results and certain PCBspecific aspects. Chemosphere 67:S79-S89

Marcoci I (1984) Analiza biologica a apelor. Romanian Academy, Bucharest

McNaughton SJ (1968) Structure and function in California grasslands. Ecology 49:962-972

OECD (2004) Organisation for Economic Cooperation and Development. Guideline for Testing of Chemicals 202 Daphnia sp. Acute Immobilisation Test and reproduction test. Paris, France

Pantle R, Buck H (1955) Die biologische Überwachung der Gewasser und die Darstellung der Ergebnisse. Gas und Wasserfach 96:604-607

Pielou EC (1977) Mathematical ecology, 2nd edn. Wiley, New York, USA, pp 291-311

Preston BL (2002) Indirect effects in aquatic ecotoxicology: implications for ecological risk assessment. Environ Manage 29:311-323

Prygiel J et al (2002) Determination of the biological diatom index (IBD NF T 90-354) results of an intercomparison exercise. J Appl Phycol 14:27-39

RIZA (2000) Analyses of water and sediments quality of water system in the Prut basin, Romania. Report of the Institute of Inland Water Management and Waste Water Treatment RIZA, The Netherlands, 2000

Rolauffs P, Stubauer I, Zahradkova S, Brabec K, Moog O (2004) Integration of the saprobic system into the European Union Water Framework Directive. Hydrobiologia 516:285-298

Schmedtje U, Liska I (2005) Intercalibration manual for the eastern continental region. Prepared for the Eastern Continental Geographical Intercalbration Group (EG GIG), Draft 6 IC/WD/170, 17 January 2005

Seco JI, Fernandez-Pereira C, Vale J (2003) A study of the leachate toxicity of metal-containing solid wastes using Daphnia magna. Ecotoxicol Environ Saf 56:339-350

Skrbic B, Durisic-Mladenovic N (2007) Principal component analysis for soil contamination with organochlorine compounds. Chemosphere $68: 2144-2152$

Spellerberg IF (2005) Monitoring ecological change, 2nd edn. Cambridge University Press, Cambridge, pp 171-173 202-219

Tinsley D, Wharfe J, Campbell D, Chown P, Taylor D, Upton J, Taylor C (2004) The use of direct toxicity assessment in the assessment and control of complex effluents in the UK: a demonstration programme. Ecotoxicology 13(5):423-436

US EPA (1978) The Selenastrum capricornutum Printz Algal Assay Bottle Test. US Environmental Protection Agency, EPA 600/9 78 018

US EPA (2002) Using algae to assess environmental conditions in wetlands. US Environmental Protection Agency, EPA 822-R-02-021

WFD (2000) Directive 2000/60/EC of the European Parliament and of the Council establishing a framework for the Community action in the field of water policy (Water Framework Directive), adopted on 23.10.2000, published in the Official Journal (OJ L 237) on 22.12.2000

Winklers HJ, Kroonenberg SB, Lychagin MY, Marin G, Rusakov GV, Kasimov NS (1998) Geochronology of priority pollutants in sedimentation zones of the Volga and Danube deltas in comparison with the Rhine delta. Appl Geochem 13(5):581-591 